\title{
Exploring the upper pH limits of nitrite oxidation: diversity, ecophysiology, and adaptive traits of haloalkalitolerant Nitrospira
}

\author{
Anne Daebeler $\mathbb{D}^{1} \cdot$ Katharina Kitzinger $\mathbb{D}^{1,5} \cdot$ Hanna Koch $^{1,6} \cdot$ Craig W. Herbold $^{1} \cdot$ Michaela Steinfeder $^{1} \cdot$ \\ Jasmin Schwarz ${ }^{1}$. Thomas Zechmeister ${ }^{2}$. Søren M. Karst ${ }^{3}$ - Mads Albertsen $\mathbb{D}^{3}$ • Per H. Nielsen $\mathbb{D}^{3}$. \\ Michael Wagner ${ }^{1,3,4} \cdot$ Holger Daims (iD) ${ }^{1,4}$
}

Received: 28 February 2020 / Revised: 1 June 2020 / Accepted: 16 July 2020 / Published online: 24 July 2020

(c) The Author(s) 2020. This article is published with open access

\begin{abstract}
Nitrite-oxidizing bacteria of the genus Nitrospira are key players of the biogeochemical nitrogen cycle. However, little is known about their occurrence and survival strategies in extreme $\mathrm{pH}$ environments. Here, we report on the discovery of physiologically versatile, haloalkalitolerant Nitrospira that drive nitrite oxidation at exceptionally high $\mathrm{pH}$. Nitrospira distribution, diversity, and ecophysiology were studied in hypo- and subsaline (1.3-12.8 g salt/l), highly alkaline ( $\mathrm{pH}$ 8.9-10.3) lakes by amplicon sequencing, metagenomics, and cultivation-based approaches. Surprisingly, not only were Nitrospira populations detected, but they were also considerably diverse with presence of members from Nitrospira lineages I, II and IV. Furthermore, the ability of Nitrospira enrichment cultures to oxidize nitrite at neutral to highly alkaline $\mathrm{pH}$ of 10.5 was demonstrated. Metagenomic analysis of a newly enriched Nitrospira lineage IV species, "Candidatus Nitrospira alkalitolerans", revealed numerous adaptive features of this organism to its extreme environment. Among them were a sodium-dependent N-type ATPase and NADH:quinone oxidoreductase next to the proton-driven forms usually found in Nitrospira. Other functions aid in $\mathrm{pH}$ and cation homeostasis and osmotic stress defense. "Ca. Nitrospira alkalitolerans" also possesses group $2 \mathrm{a}$ and $3 \mathrm{~b}[\mathrm{NiFe}]$ hydrogenases, suggesting it can use hydrogen as alternative energy source. These results reveal how Nitrospira cope with strongly fluctuating $\mathrm{pH}$ and salinity conditions and expand our knowledge of nitrogen cycling in extreme habitats.
\end{abstract}

Supplementary information The online version of this article (https:// doi.org/10.1038/s41396-020-0724-1) contains supplementary material, which is available to authorized users.

Anne Daebeler

anne.daebeler@univie.ac.at

$\triangle$ Holger Daims

holger.daims@univie.ac.at

1 University of Vienna, Centre for Microbiology and Environmental Systems Science, Division of Microbial Ecology, Vienna, Austria

2 Biological Station Lake Neusiedl, 7142 Illmitz, Austria

3 Center for Microbial Communities, Department of Chemistry and Bioscience, Aalborg University, Aalborg, Denmark

4 University of Vienna, The Comammox Research Platform, Vienna, Austria

5 Present address: Max Planck Institute for Marine Microbiology, Department of Biogeochemistry, Bremen, Germany

6 Present address: Department of Microbiology, Radboud University, Nijmegen, The Netherlands

\section{Introduction}

Chemolithoautotrophic nitrite-oxidizing bacteria (NOB) are key players of the nitrogen cycle in virtually all oxic habitats including soil, freshwater and marine ecosystems, engineered environments, and geothermal springs [1-9]. By catalyzing the second step of nitrification, NOB are the main biological source of nitrate, which is an important source of nitrogen and a terminal electron acceptor used by a plethora of other organisms. In most terrestrial and engineered environments, the predominant known NOB are uncultured members of the genus Nitrospira [1, 10-13]. Within this highly diverse genus, six phylogenetic lineages (named lineage I to VI) have been described, some of which seem to colonize distinct habitat types $[1,4,8,14,15]$. Recent studies revealed an unexpected metabolic versatility of Nitrospira beyond nitrite oxidation, such as aerobic growth on hydrogen or formate $[16,17]$ and, most surprisingly, the capability of complete ammonia oxidation to nitrate by some representatives (the comammox organisms) $[18,19]$. 


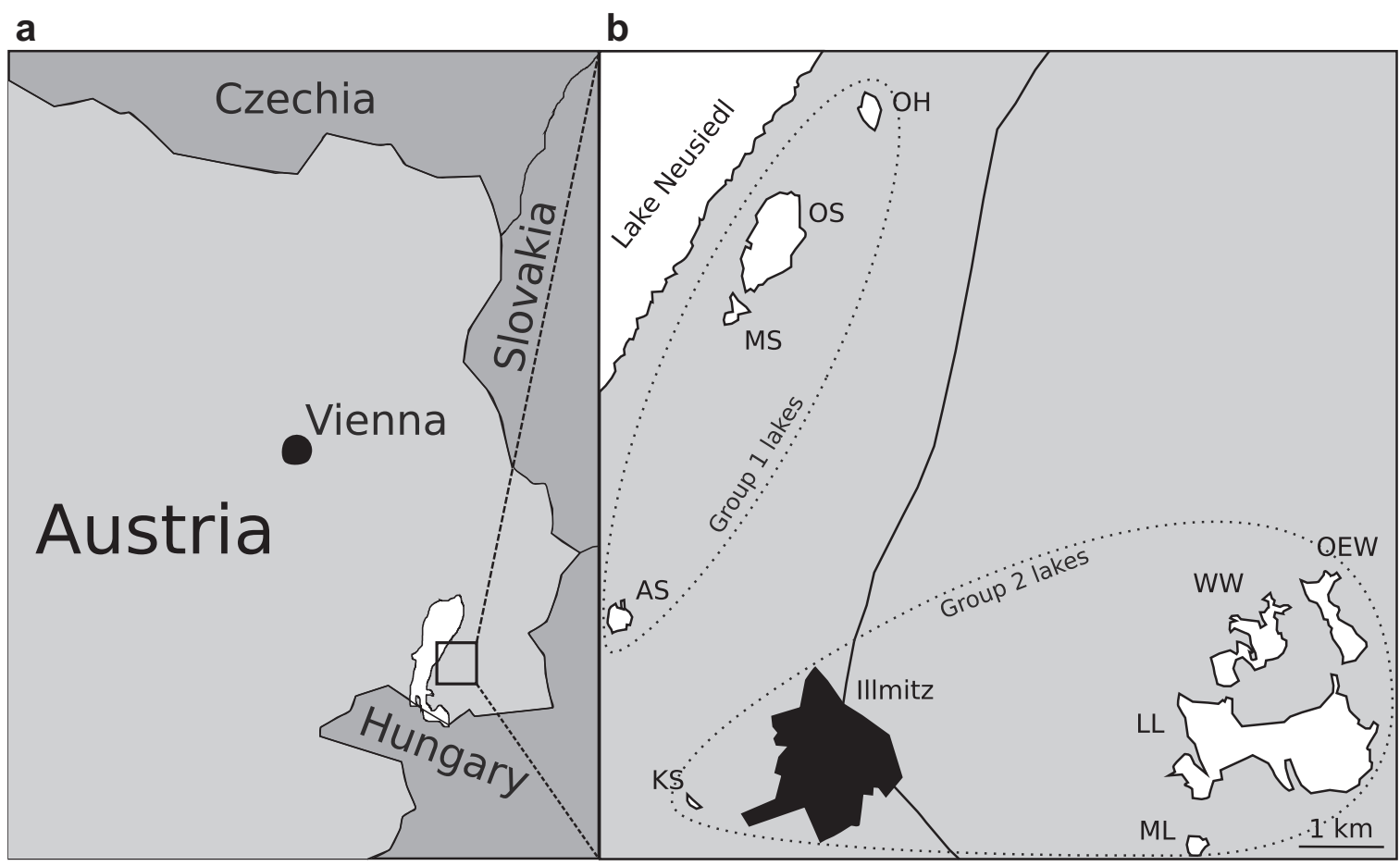

Fig. 1 Map of the sampled saline-alkaline lakes. a Location of the sampling region in Austria. b Geographic location of the sampled lakes in the national park "Neusiedler See-Seewinkel", Burgenland, Austria. The lakes are shown in white with the corresponding identifier abbreviations (AS Albersee, MS Mittlerer Stinker-See, OS Oberer
Stinker, OH Obere Höll-Lacke, KS Krautingsee, WW Westliche Wörthenlacke, OEW Östliche Wörthenlacke, LL Lange Lacke, ML Südliche Martinhoflacke). Only lakes sampled for this study are shown. Dashed circles enclose lakes with similar Nitrospira communities (see Fig. 3).
Haloalkaline systems are highly productive environments that harbor diverse, haloalkaliphilic microbial communities capable of rapid biogeochemical cycling [20-28], but knowledge of the responsible microbes and their ecology, in particular of NOB, is fragmentary [21, 27, 29, 30]. In a pioneering study, the hitherto only known facultatively alkaliphilic nitrite oxidizer, Nitrobacter alkalicus, was isolated and analyzed regarding its morphology and tolerance toward elevated $\mathrm{pH}$ of around 10 [29].

Shallow, saline-alkaline lakes are a characteristic of the Pannonian steppe in Central Europe-an ecosystem which extends into eastern Austria and is protected in the national park "Neusiedler See-Seewinkel". The salinity of these lakes varies within the hyposaline range and the $\mathrm{pH}$ is generally above 9 [31, 32]. These lakes exhibit a high turbidity caused by inorganic suspended particles and/or high humic substance content and frequently dry out during summer months [31]. Plant material of the shoreline vegetation and excrement of aquatic birds provide organic carbon, inorganic nitrogen and phosphorous inputs [33, 34]. Taken together, shallowness, intermittent character (periodic desiccation), high turbidity, alkaline $\mathrm{pH}$, polyhumic organic carbon concentration, hypertrophic conditions and during summer high daily water temperature fluctuation create multiple extreme environmental conditions in these lakes [35].

In the present study, we obtained deeper insights into the biology of Nitrospira in haloalkaline systems. An investigation of the NOB community structure in sediments of saline-alkaline lakes in the national park "Neusiedler SeeSeewinkel", Burgenland, Austria (Fig. 1), by amplicon sequencing subsequently allowed for the targeted study of the ecophysiology and genomic adaptations in newly discovered alkalitolerant Nitrospira.

\section{Materials and methods}

\section{Sediment sampling and enrichment cultures of alkalitolerant Nitrospira}

Triplicate sediment samples ( 10g) from nine salinealkaline lakes in the national park "Neusiedler See-Seewinkel", Burgenland, Austria (Fig. 1) were sampled from the top $10 \mathrm{~cm}$ of the sediments within a radius of five $\mathrm{m}$ in October 2013. The water $\mathrm{pH}$ and conductivity were measured for each lake at the time of sampling with a a SenTix 41 electrode and a WTW Multiline field instrument with a 
Table 1 Environmental properties determined for sediments, pore water (indicated by ${ }^{\#}$ ) and lake water (indicated by *) sampled in October 2013 from nine saline-alkaline lakes in the national park "Neusiedler See-Seewinkel", Burgenland, Austria.

\begin{tabular}{|c|c|c|c|c|c|c|c|c|c|}
\hline Lake (group) & AS (1) & MS (1) & OS (1) & $\mathrm{OH}(1)$ & KS (2) & WW (2) & OEW (2) & LL (2) & ML (2) \\
\hline $\mathrm{pH}^{*}$ & 9.98 & 9.77 & 10.3 & 9.82 & 9.71 & 9.18 & 9.16 & 9.42 & $8.9^{\S}$ \\
\hline Conductivity $[\mathrm{mS} / \mathrm{cm}]^{*}$ & $16.0^{\S}$ & $6.1^{\S}$ & $4.4^{\S}$ & $4.0^{\S}$ & 3.88 & 2.79 & 4.66 & 4.19 & $1.7^{\S}$ \\
\hline Salinity $[\mathrm{g} / \mathrm{l}]]^{*}$ & 12.8 & 4.88 & 3.52 & 3.2 & 3.1 & 2.23 & 3.73 & 3.35 & 1.36 \\
\hline $\mathrm{DOC}[\mathrm{mg} / \mathrm{l}]^{\#}$ & NA & NA & NA & NA & 531.75 & 139.61 & 280.22 & 138.05 & NA \\
\hline $\mathrm{TN}[\mathrm{mg} / \mathrm{l}]^{\#}$ & NA & NA & NA & NA & 33.54 & 4.09 & 15.75 & 5.69 & NA \\
\hline $\mathrm{NH}_{4}{ }^{-}-\mathrm{N}[\mu \mathrm{g} /]^{\#}$ & NA & 166 & NA & 1948 & 259 & 179 & 298 & 109 & 578 \\
\hline $\mathrm{NO}_{2}{ }^{-}-\mathrm{N}[\mu \mathrm{g} / 1]^{\#}$ & NA & 11 & NA & 398 & 30 & 4 & 13 & 7 & 12 \\
\hline $\mathrm{NO}_{3}{ }^{-}-\mathrm{N}[\mu \mathrm{g} / 1]^{\#}$ & NA & 179 & NA & 328 & 146 & 212 & 129 & 155 & 185 \\
\hline $\mathrm{PO}_{4}{ }^{-}-\mathrm{P}[\mu \mathrm{g} / 1]^{\#}$ & NA & 3100 & NA & 7850 & 133 & 58 & 1420 & 1840 & 774 \\
\hline Carbonate $[\%]$ & 20.6 & 30.5 & 17.7 & 22.2 & 17.7 & 46.1 & 44.5 & 41.2 & 5.8 \\
\hline Ntot [\%] & 0.087 & 0.109 & 0.092 & 0.081 & 0.135 & 0.293 & 0.585 & 0.164 & 0.032 \\
\hline $\mathrm{Fe}[\mathrm{mol} / \mathrm{gDW}]$ & 7.48 & 10 & 10.16 & 10.33 & 14.97 & 12.06 & NA & 12.34 & 8.1 \\
\hline $\mathrm{Mn}[\mathrm{mol} / \mathrm{gDW}]$ & 2.86 & 2.47 & 2.31 & 2.42 & 2.69 & 2.03 & NA & 3.3 & 7.25 \\
\hline $\mathrm{Cu}[\mathrm{mol} / \mathrm{gDW}]$ & 0.1 & 0.21 & 0.08 & 0.12 & 0.1 & 0.15 & NA & 0.19 & 0.11 \\
\hline $\mathrm{Zn}[\mathrm{mol} / \mathrm{gDW}]$ & 0.08 & 0.06 & 0.07 & 0.1 & 0.1 & 0.11 & NA & 0.29 & 0.05 \\
\hline
\end{tabular}

Values marked with $\S$ denote data derived from the literature [32]. Missing data marked with NA (not available) was due to insufficient material for determination. Salinity values were estimated using a regionally constant correction factor [31]. Per cent units for carbonate and $\mathrm{N}_{\text {tot }}$ refer to the percentage weight of dried sediment. See Fig. 1 for lake abbreviations.
TetraCon 325, respectively. Salinity was inferred from conductivity based on a conversion factor, which had previously been established in experiments [31]. Dissolved organic carbon (DOC) concentrations were analyzed from sediment pore water filtered through precombusted glass fiber filters (GF/F, Whatman) and measured on a Total Carbon Analyzer (Sievers M9 Laboratory Analyzer, GE Analytical Instruments, Boulder, Colorado, U.S.A.). Nutrient concentrations (total nitrogen [TN], phosphorus-P, ammonium-N, nitrite-N, and nitrate-N) in lake waters were determined from sediment pore water using German Standard Methods [36]. Aliquots of both sediment and lake water samples were used as inoculum for nitrite oxidizer enrichment cultures, and the remaining material was stored at $-20{ }^{\circ} \mathrm{C}$ for molecular and chemical analyses. Concentration measurements of carbonate, total nitrogen, and trace metals in sediment samples were performed by the Austrian Agency for Health and Food safety (AGES $\mathrm{GmbH}$, Vienna, Austria) according to their standard protocols. The results of the chemical measurements are listed in Table 1.

Enrichment cultures of alkalitolerant NOB were established in mineral nitrite medium with a $\mathrm{pH}$ of 9-10.2 at $28^{\circ} \mathrm{C}$. The medium was composed to reflect the chemical properties of the saline-alkaline lakes; however, trace elements were added as in Koch et al. [1]. The medium had the following composition: $1000 \mathrm{ml}$ of distilled, millipore filtered water, $37 \mathrm{mg} \mathrm{KCl}, 53 \mathrm{mg} \mathrm{CaCl}{ }_{2}, 740 \mathrm{mg} \mathrm{Na}_{2} \mathrm{SO}_{4}$, $390 \mathrm{mg} \mathrm{MgCl}_{2}, 150 \mathrm{mg} \mathrm{KH}_{2} \mathrm{PO}_{4}, 700 \mathrm{mg} \mathrm{Na} \mathrm{CO}_{3}, 34 \mu \mathrm{g}$
$\mathrm{MnSO}_{4} \times \mathrm{H}_{2} \mathrm{O}, \quad 50 \mu \mathrm{g} \mathrm{H}_{3} \mathrm{BO}_{3}, 70 \mu \mathrm{g} \quad \mathrm{ZnCl}_{2}, 72.6 \mu \mathrm{g}$ $\mathrm{Na}_{2} \mathrm{MoO}_{4}, \times 2 \mathrm{H}_{2} \mathrm{O}, 20 \mu \mathrm{g} \mathrm{CuCl} \times 2 \mathrm{H}_{2} \mathrm{O}, 24 \mu \mathrm{g} \mathrm{NiCl} \mathrm{Nu}_{2} \times 6$ $\mathrm{H}_{2} \mathrm{O}, 80 \mu \mathrm{g} \mathrm{CoCl} \mathrm{C}_{2} \times 6 \mathrm{H}_{2} \mathrm{O}, 1 \mathrm{mg} \mathrm{\textrm {FeSO } _ { 4 }} \times 7 \mathrm{H}_{2} \mathrm{O}$. The $\mathrm{pH}$ was monitored using indicator stripes (Macherey-Nagel) and a pH meter (WTW, Germany). Physiological tests were performed with selected Nitrospira enrichment cultures to determine their $\mathrm{pH}$ tolerance (with tested $\mathrm{pH}$ values ranging from 7.6 to 11) and nitrite concentration optimum of growth (with tested concentrations ranging from 0.15 to $1 \mathrm{mM}$ $\mathrm{NO}_{2}{ }^{-}$). A detailed description of the cultivation procedure and physiological experiments is provided in the Supplementary text.

\section{Molecular analyses of Nitrospira community structures}

DNA extraction, PCR amplification, cloning, Illumina amplicon sequencing, and phylogenetic analyses of $16 \mathrm{~S}$ rRNA gene and $n x r B$ sequences, as well as rRNA-targeted fluorescence in situ hybridization (FISH), were performed as described in the Supplementary text.

\section{Metagenome sequencing, Nitrospira genome assembly, and analyses of genes putatively involved in haloalkalitolerance}

Cells of the "Ca. Nitrospira alkalitolerans" enrichment culture were harvested by centrifugation at $20.000 \times g$ for $15 \mathrm{~min}$ and the cell pellet was used for DNA extraction 


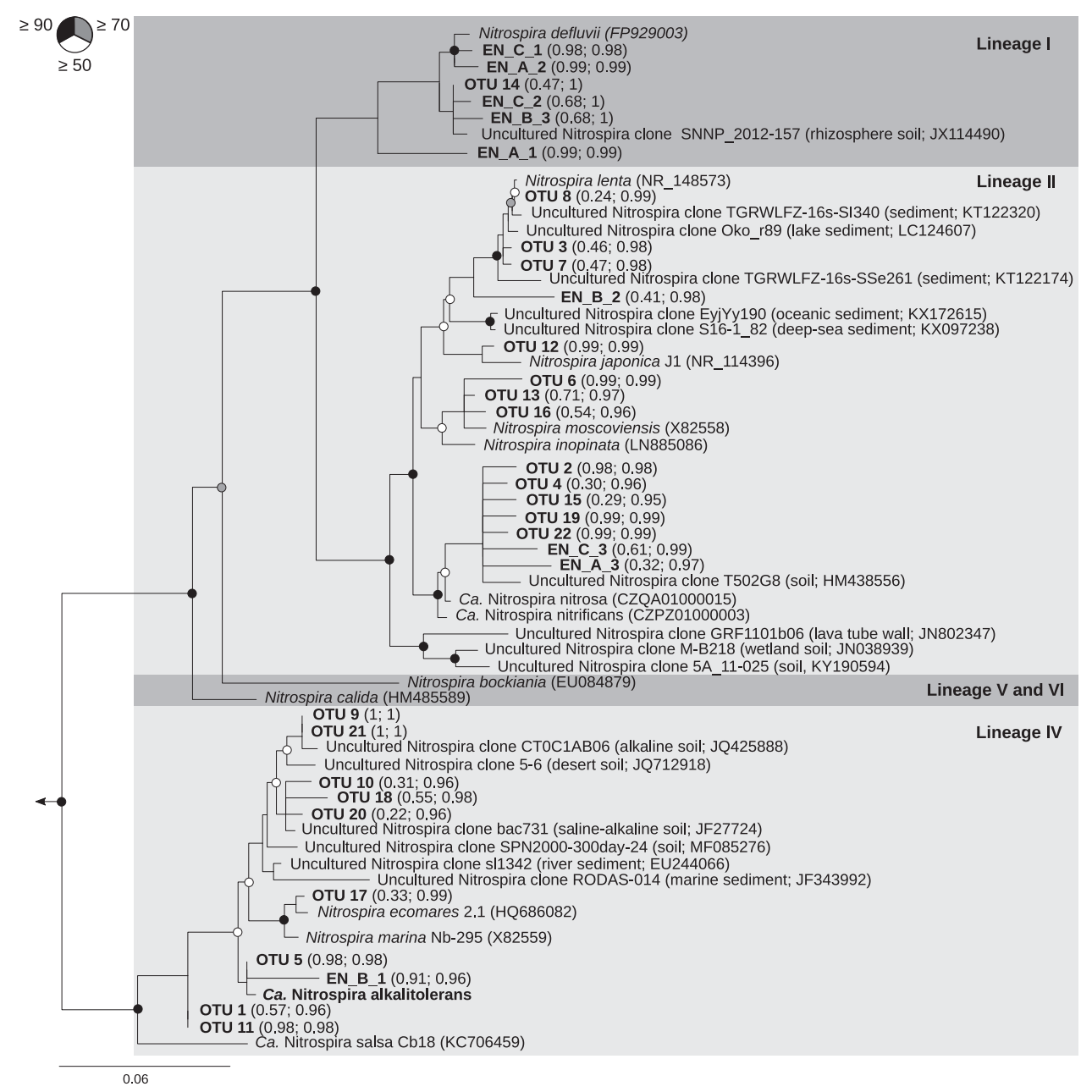

Fig. 2 Phylogenetic maximum likelihood analysis based on the $16 \mathrm{~S}$ rRNA gene sequences of selected representatives from the genus Nitrospira and of the Nitrospira members detected in sediments from nine saline-alkaline lakes. Sequences obtained in this study are printed in bold. "Ca. N. alkalitolerans" is the Nitrospira species cultured and further analyzed in this study. The tree was constructed using full length sequences and a 50\% conservation filter resulting in 1310 valid alignment positions. Shorter sequences from this study, generated through amplicon and Sanger sequencing were added to the tree using the Evolutionary Placement Algorithm (EPA) without changing

according to Angel et al. [37]. Metagenome sequencing, assembly, binning, and annotation procedures are described in the Supplementary text.

Specific genomic features of "Ca. N. alkalitolerans", which are likely important for its adaptation to haloalkaline conditions, were identified by comparison to previously sequenced genomes of Nitrospira and Nitrospina that did not originate from haloalkaline habitats by using the OrthoFinder software [38] with default settings. Organisms used in these analyses were Nitrospira moscoviensis [17] and $N$. defluvii [39] (both canonical NOB), N. inopinata $[18,40]$ (moderately thermophilic comammox organism), "Ca. N. nitrosa" and "Ca. N. nitrificans" [19] (two the overall tree topology. Numbers in brackets behind these sequences firstly denote the likelihood score of the exact placement and secondly the cumulative likelihood score of the placement within the cluster. Filled, gray, and open circles denote branches with $\geq 90 \%, \geq 70 \%$ and $\geq 50 \%$ bootstrap support, respectively. Leptospirillum ferrooxidans (AJ237903), Ca. Magnetobacterium bavaricum (FP929063), Thermodesulfovibrio yellowstonii DSM 11347 (CP001147), and Ca. Methylomirabilis oxyfera (FP565575) were used as outgroup. The scale bar indicates $6 \%$ estimated sequence divergence.

mesophilic comammox organisms), and Nitrospina gracilis [41] (marine canonical nitrite oxidizer). Phylogenetic trees and the amino acid alignments of ATPase subunit $c$ were reconstructed as described in the Supplementary text.

\section{Results and discussion}

\section{Community composition of Nitrospira in the saline- alkaline lakes}

Members of the genus Nitrospira are the most diverse and widespread known NOB. However, reports of Nitrospira 
Fig. 3 Normalized abundances of Nitrospira 16S rRNA gene phylotypes detected in triplicate sediment samples from nine saline-alkaline lakes. Nitrospira communities are grouped by hierarchical clustering on the $y$-axis, and OTUs are grouped by phylogenetic affiliation on the $x$-axis. Lake names are abbreviated as in Fig. 1. Lin. IV, Nitrospira lineage IV ; Lin. II, Nitrospira lineage II; I, Nitrospira lineage I; Freq normalized frequency counts; Grp.1, group 1 lakes; Grp.2, group 2 lakes (see also Fig. 1).

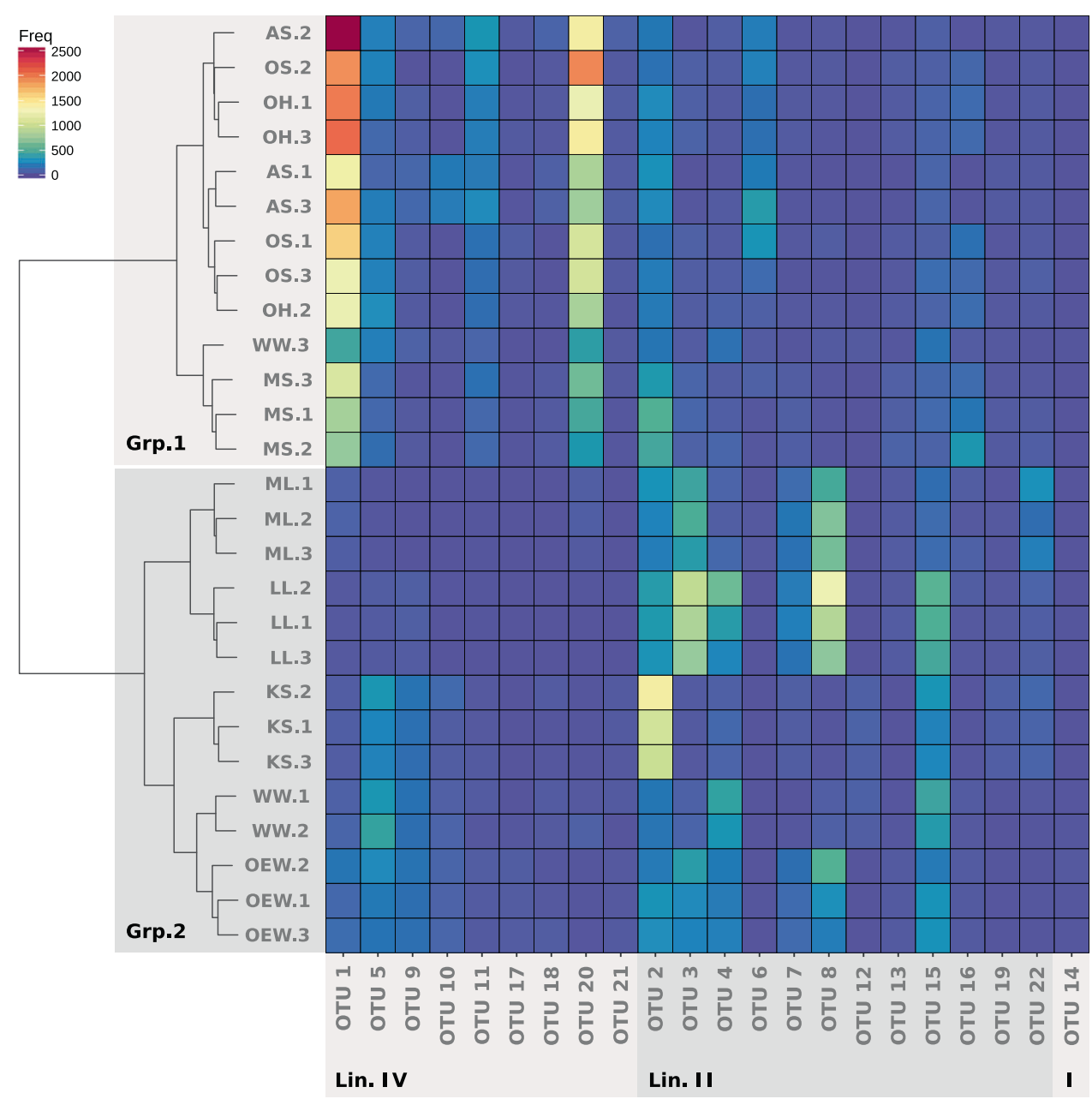

occurrence in alkaline habitats are scarce [23, 30], and a systematic assessment of their presence and activity in such extreme environments is missing. In this study, we discovered and investigated unusually alkalitolerant Nitrospira in saline-alkaline lakes of the national park "Neusiedler See-Seewinkel", Burgenland, Austria using targeted amplicon profiling of the 16S rRNA gene and $n x r B$, of which the latter encodes the beta-subunit of nitrite oxidoreductase (the key enzyme for nitrite oxidation). In sediment samples from nine lakes, we detected phylogenetically diverse Nitrospira phylotypes which were affiliated with Nitrospira lineages I, II and IV (Fig. 2) [1].

The genomes of sequenced Nitrospira possess one to six paralogous copies of $n x r B$, and the $n x r B$ copy numbers per genome remain unknown for the majority of uncultured Nitrospira [42]. This large variability likely affects relative abundance estimations of Nitrospira OTUs based on $n x r B$ amplicon data. In contrast, all sequenced Nitrospira genomes contain only one ribosomal RNA ( $r r n)$ operon. Therefore, our further assessment of the Nitrospira community structures relies on the 16S rRNA gene amplicon datasets.
The estimated alpha-diversity of Nitrospira 16S rRNA gene phylotypes was compared across the nine examined lakes (Fig. S1). The inverse Simpson's index of the Nitrospira communities was negatively correlated with $\mathrm{pH}$ and the nitrite concentration $(p=0.00004$, Tau-b $=-0.53$ for $\mathrm{pH}$ and $p=0.03$, Tau-b $=-0.36$ for nitrite). The decrease of Nitrospira diversity with increasing $\mathrm{pH}$ may indicate that only specific Nitrospira phylotypes tolerate highly alkaline conditions.

The Nitrospira communities clustered into two distinct major groups (Fig. 3). Group 1 mainly comprised the communities from those lakes, which are located closely to the shore of the much larger Lake Neusiedl, whereas group 2 contained the communities from the remaining lakes that are farther away from Lake Neusiedl (Fig. 1). The average $\mathrm{pH}$ and salinity in the water of lakes from the group 1 cluster were $9.97 \pm 0.24$. and $6.1 \pm 4.1 \mathrm{~g} / \mathrm{l}$, respectively. These values were significantly higher (Welch's $t$-test; $p=$ 0.00001 for $\mathrm{pH}$ and $p=0.017$ for salinity) than the mean $\mathrm{pH}$ of $9.37 \pm 0.26$ and salinity of $2.74 \pm 0.88 \mathrm{~g} / \mathrm{l}$ in the group 2 lakes (Table 1). None of the other determined lake properties at time of sampling differed significantly between 
the two groups. The Nitrospira phylotypes with the highest relative abundance in the sediments from group 1 were OTU1 and OTU20, both affiliated with Nitrospira lineage IV, whereas these OTUs were nearly absent from the sediments of the lakes in group 2 (Fig. 3). In contrast, the predominant phylotypes in the group 2 lake sediments were affiliated with Nitrospira lineage II (Fig. 3). Consistent with these results, a principal coordinate analysis showed a clear separation of the Nitrospira communities with the same two groups separated on the first axis of the ordination (Fig. S2). These results indicate a strong influence of $\mathrm{pH}$ and salinity on the composition of the Nitrospira communities. Members of Nitrospira lineage IV are adapted to saline conditions and are commonly found in marine ecosystems [15, 43-47]. However, to date no Nitrospira species have been described to tolerate elevated $\mathrm{pH}$ conditions. Our results show that a substantial diversity of Nitrospira is able to colonize alkaline environments. The data also indicate a niche differentiation between lineages IV and II in salinealkaline lakes, which likely includes a higher tolerance of the detected lineage IV organisms toward an elevated $\mathrm{pH}$ and salinity.

\section{Metagenome sequencing and physiology of alkalitolerant Nitrospira enrichments}

Following the inoculation of mineral nitrite medium flasks with sediment and/or water samples from four salinealkaline lakes (LL, WW, KS and OEW; abbreviations see Table 1), we initially obtained 17 enrichment cultures that oxidized nitrite to nitrate. Based on FISH analyses with Nitrospira-specific 16S rRNA gene-targeted probes and Sanger sequencing of cloned 16S rRNA genes, several of these preliminary enrichment cultures contained co-existing phylotypes from Nitrospira lineages I, II, and IV as well as from the genus Nitrobacter (data not shown). Members of the genera Nitrotoga and Nitrospina were screened for by FISH or PCR, but were not detected.

We used three of the enrichments which contained only Nitrospira NOB and originated from different lakes (referred to as EN_A from lake OEW, EN_B from lake LL, and EN_C from lake WW comprising $~ 35 \%$ Nitrospira in relation to the total microbial community based on FISH analysis) to determine the $\mathrm{pH}$ range for activity of the enriched Nitrospira members. Enrichment cultures EN_A and EN_C contained phylotypes from Nitrospira lineages I and II, while EN_B contained phylotypes from lineages I, II, and IV as determined by 16 rRNA gene amplicon cloning and Sanger sequencing (Fig. 2). The continued presence of these Nitrospira phylotypes for more than 2 years, despite several serial dilution transfers, demonstrates their tolerance to the alkaline incubation conditions and suggests that they were native to the saline-alkaline environment which they were sampled from. Hence, we conclude that at least the highly similar uncultured Nitrospira OTUs detected by amplicon sequencing (Fig. 2) were most likely also native inhabitants of the saline-alkaline lakes. Aliquots of each enrichment culture were incubated with nitrite as the sole added energy source for six weeks at pH 7.61-7.86 and 9-9.04, respectively. During this period, $\mathrm{pH}$ had no significant effect on nitrite utilization (Pearson correlation coefficient $\geq 0.96$ with, $p \leq 0.01$ for all three enrichments) and nitrate production (Pearson correlation coefficient $\geq 0.98$ with, $p \leq 0.01$ for all three enrichments) over time for any of the three enrichments (Fig. S3). Subsequently, the enrichment culture aliquots that had been incubated at $\mathrm{pH}$ 9-9.04 were sequentially incubated at $\mathrm{pH}$ 9.97-10, 10.24-10.52, and 10.72-11.02 for eight to nine days at each $\mathrm{pH}$ (Table S1). For all three enrichments, the observed nitrate production tended to be slower at $\mathrm{pH}$ 9.97-10 and 10.24-10.52 than at pH 9-9.04 (Fig. S3 and S4). At pH 10.72-11.02, no nitrite consumption was detected (Fig. S4). The trends observed at pH 10.24-10.52 and above were in stark contrast to the persistently high nitrite-oxidizing activity of the enrichments when routinely cultured at $\mathrm{pH} 9-10$ for several weeks. While it was not possible to determine based on our data whether all Nitrospira phylotypes present in the three enrichments responded equally to the tested $\mathrm{pH}$ conditions, we can conclude that the activity of at least some Nitrospira remained unaffected up to $\mathrm{pH} 9$ and had an upper limit between $\mathrm{pH} 10.5$ and 10.7. This is remarkable, because previously enriched or isolated Nitrospira strains were not cultivated above $\mathrm{pH} 8.0$ except for two Nitrospira cultures from geothermal springs, which showed activity up to $\mathrm{pH}$ 8.8 [4] or $\mathrm{pH} 9.0$ [7]. To our knowledge, this is the first report of nitrite oxidation by Nitrospira at $\mathrm{pH}$ values above 9 and as high as 10.5 .

Further analyses focused on one additional enrichment, which had been inoculated with sediment from lake Krautingsee, belonging to the group 2 of the analyzed lakes (KS, Table 1). In contrast to the other enrichment cultures, this enrichment contained only lineage IV Nitrospira based on FISH analysis (Fig. 4a). Nitrospira-specific, 16S rRNA gene and $n x r B$-targeted PCR and phylogeny detected one phylotype from Nitrospira lineage IV that was related to other phylotypes detected from the lakes, specifically OTU 5 and EN_B_1 (16S rRNA gene, 100\% and 98\% nucleotide sequence identity, respectively; Fig. 2) and OTU 2 ( $\mathrm{nxrB}$, 98.5\% nucleotide sequence identity; Fig. S5). Both these OTU phylotypes occurred in most of the analyzed lakes (Fig. 3). Thus, the closely related enrichment from lake KS may represent Nitrospira that could adapt to a relatively broad range of conditions, while some of the other OTUs were more abundant in specific lakes only (Fig. 3). The enriched Nitrospira reached a high relative abundance in 
a

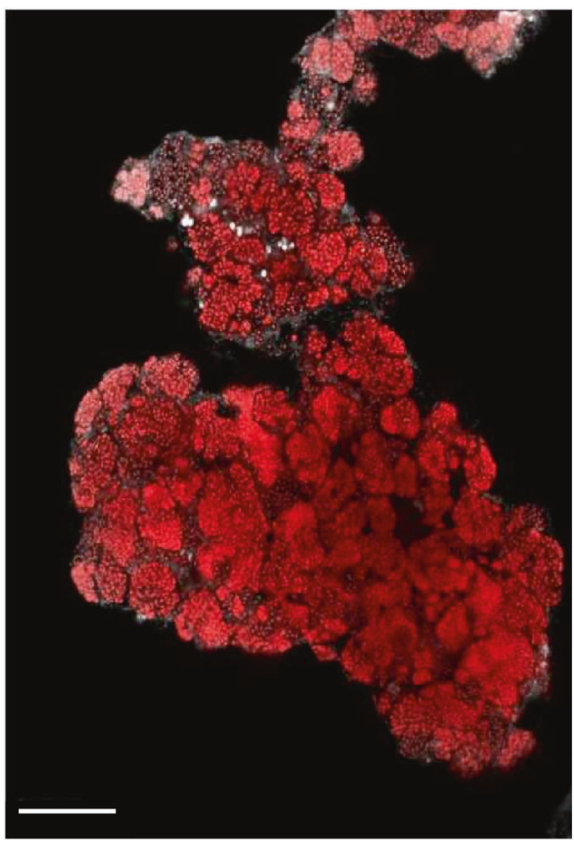

Fig. 4 Visualization and metagenomic analysis of the " $\mathrm{Ca} . \mathrm{N}$. alkalitolerans" enrichment. a FISH image showing dense cell clusters of " $\mathrm{Ca}$. N. alkalitolerans" in the enrichment culture. The "Ca. N. alkalitolerans" cells appear in red (labeled by probe Ntspa1151 which has 1 mismatch at the 3' end to the 16S rRNA gene sequence of " $\mathrm{Ca}$. N. alkalitolerans"; the absence of lineage II Nitrospira in the enrichment culture was confirmed by the application of the competitor oligonucleotides c1Ntspa1151 and c2Ntspa1151 as indicated in

the enrichment culture of $\sim 60 \%$ of all bacteria based on metagenomic read abundance (see below) and observation by FISH.

High-throughput metagenome sequencing, scaffold assembly, and binning revealed that the enrichment contained three Nitrospira strains that could be separated into three genome bins based on sequence coverage data (Table S2, Fig. S6). No other NOB were identified in the metagenome, and the three Nitrospira bins represented the most abundant organisms in the enrichment culture (Fig. 4b). Since the genome-wide average nucleotide identity (gANI) values were above the current species threshold of 95\% [48] (Table S2), the three bins likely represented very closely related strains of the same Nitrospira lineage IV species with unique genetic components. From the predominant (based on coverage data) Nitrospira sequence bin, an almost complete metagenome-assembled genome (MAG) was reconstructed, which met the criteria for a "high-quality draft" genome [49] (Table S2), and used for comparative genomic analysis. Genome-wide, pairwise comparison of the gANI and average amino acid (gAAI) identity between this MAG and Nitrospira marina as the only other genome-sequenced and cultured Nitrospira lineage IV representative resulted in values of 80.1 and
77.3, respectively. The 16S rRNA gene, which had been retrieved from the MAG, was $97.90 \%$ identical to the $16 \mathrm{~S}$ rRNA gene of N. marina, $97.87 \%$ identical to "N. strain Ecomares 2.1", $94.92 \%$ to "Ca. N. salsa", and $94.51 \%$ to "Nitrospira strain Aa01", which are the other cultured members of Nitrospira lineage IV [15, 43, 46, 47]. These values are below the current species threshold of 98.7-99\% for 16S rRNA genes [50]. Based on the low gANI and 16S rRNA gene sequence identities to described Nitrospira species, and additionally considering the distinct haloalkalitolerant phenotype (see also below), we conclude that the enriched Nitrospira represent a new species and propose "Ca. Nitrospira alkalitolerans" as the tentative name.

The enrichment culture was maintained at a $\mathrm{pH}$ of 9-10 and a salt concentration of $2 \mathrm{~g} / \mathrm{l}$, resembling the natural conditions in the saline-alkaline lakes based on available data from 5 years. " $\mathrm{Ca}$. N. alkalitolerans" grew in dense flocks (Fig. 4a), thereby possibly relieving the $\mathrm{pH}$ stress [51]. Its nitrite-oxidizing activity was not affected when the $\mathrm{pH}$ in the cultivation medium decreased below 8. However, no nitrite oxidation was observed when the enrichment culture was transferred into medium with $4 \times$ to $8 \times$ higher salt concentrations, the latter resembling marine conditions. Thus, " $\mathrm{Ca}$. N. alkalitolerans" is best described as a 


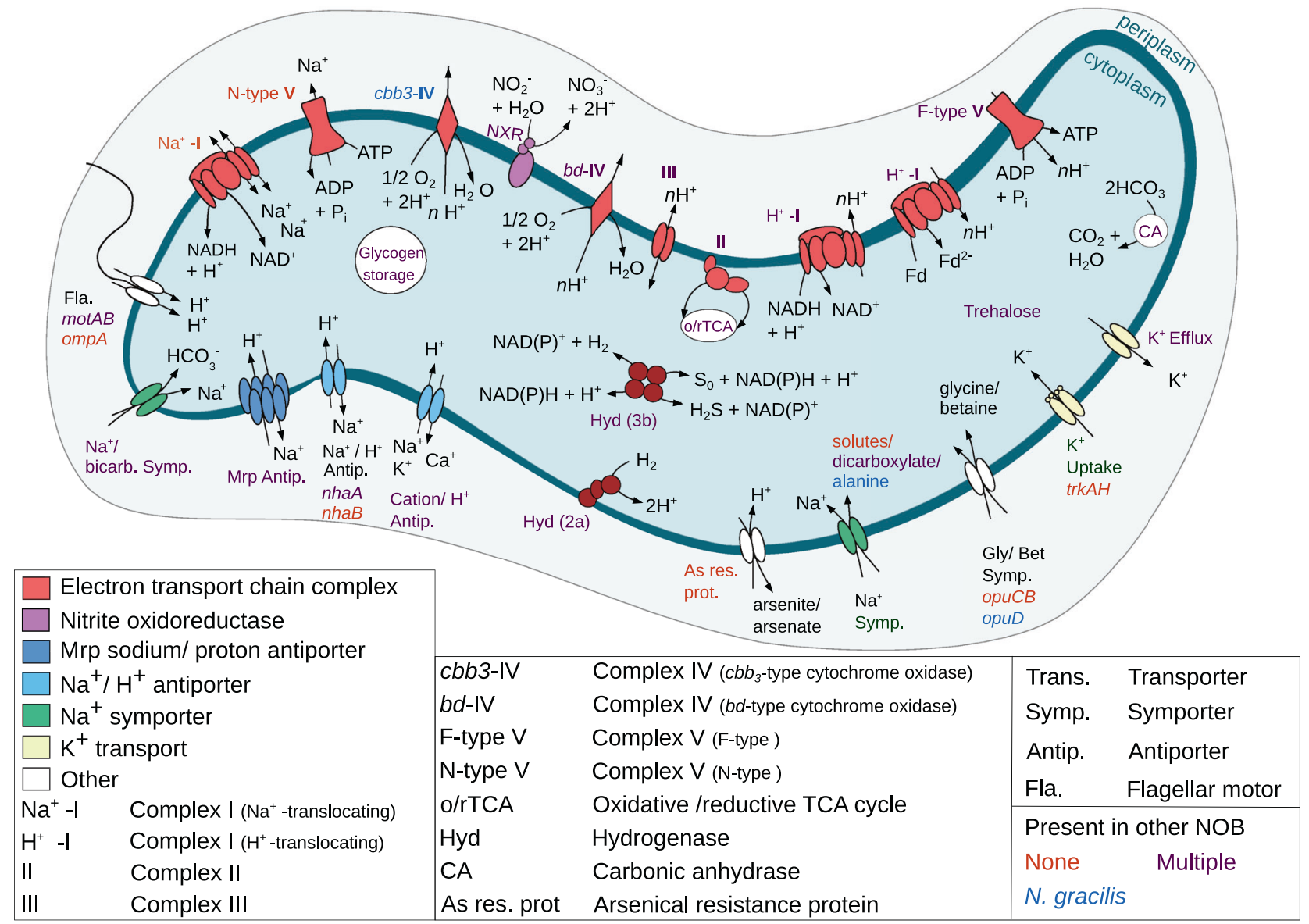

Fig. 5 Cell metabolic cartoon constructed from the genome annotation of “ $\boldsymbol{C a}$. N. alkalitolerans". Features putatively involved in the adaptation to high alkalinity and salinity, and selected core metabolic pathways of chemolithoautotrophic nitrite-oxidizing Nitrospira, are shown. Note that the transport stoichiometry of the ion transporters in " $\mathrm{Ca}$. N. alkalitolerans" remains unknown. Colors of text labels indicate whether adaptive features are present (i.e., have homologs) in the genomes of other NOB (red, feature is not present in any other characterized NOB; blue, feature is present only in the marine Nitrospina gracilis; purple, feature is present in several other characterized NOB).

\section{Genomic adaptations to the saline-alkaline environment}

As described below, comparative genomic analysis of " $\mathrm{Ca}$. $\mathrm{N}$. alkalitolerans" revealed several features that distinguish this organism from other known NOB and likely form the basis of its tolerance toward elevated alkalinity and salinity (Fig. 5).

\section{Cytoplasmic $\mathrm{pH}$ and ion homeostasis}

At high $\mathrm{pH}$, alkaliphilic and alkalitolerant microbes maintain a higher transmembrane electrical potential $(\Delta \Psi)$ component of the proton motive force (PMF) than usually found in neutrophiles. The high $\Delta \Psi$ is required to maintain PMF, because the $\Delta \mathrm{pH}$ component of the PMF is reversed when the extracellular $\mathrm{pH}$ is higher than the intracellular $\mathrm{pH}$ [54]. Like in neutrophiles, the $\Delta \Psi$ of alkaliphiles is negative 
inside the cell relative to the outside [54]. Furthermore, the intracellular $\mathrm{pH}$ must be kept below the (extremely) alkaline extracellular $\mathrm{pH}$. At elevated salinity, resistance against high salt concentrations is an additional, fundamental necessity for survival. All this requires a tightly regulated $\mathrm{pH}$ and ion homeostasis, in which cation transmembrane transporters play key roles [54-56]. The " $\mathrm{Ca}$. N. alkalitolerans" genome codes for various $\mathrm{Na}^{+}$-dependent transporters (Fig. 5, Table S3) including secondary $\mathrm{Na}^{+} / \mathrm{H}^{+}$ antiporters that are involved in $\mathrm{pH}$ homeostasis in other organisms: two copies of a group 3 Mrp-type $\mathrm{Na}^{+} / \mathrm{H}^{+}$ antiporter $[57,58]$ encoded by the seven genes $\operatorname{mrp} A-G$, and monovalent cation-proton antiporters of the types NhaA and $\mathrm{NhaB}$, each of which is encoded by a single gene [59]. The Mrp antiporter is crucial for growth at high $\mathrm{pH}$ and elevated salinity in alkaliphilic Halomonas spp. and Bacillus spp., where it exports $\mathrm{Na}^{+}$and imports $\mathrm{H}^{+}$, thus contributing to the maintenance of a lower intracellular $\mathrm{pH}$ compared to the environment (e.g., cytoplasmic $\mathrm{pH} 8.3$ at external $\mathrm{pH} \sim 10.5$ ) [[60] and references cited therein, [55]]. The Mrp proteins may form a large surface at the outside of the cytoplasmic membrane that could support proton capture under alkaline conditions [54, 57]. Nha-type antiporters are widely distributed among non-extremophilic and extremophilic organisms [55]. Being involved in the homeostasis of $\mathrm{Na}^{+}$ and $\mathrm{H}^{+}$, they are important for survival under saline and/or alkaline conditions [56]. In E. coli, NhaA is regulated by the cytoplasmic $\mathrm{pH}$ and it catalyzes the import of $2 \mathrm{H}^{+}$with the concurrent export of one $\mathrm{Na}^{+}$. This electrogenic activity is driven by $\Delta \Psi$ and maintains $\mathrm{pH}$ homeostasis at elevated external $\mathrm{pH}$ [[52] and references cited therein]. The simultaneous presence of the two antiporters NhaA and NhaB has been associated with halophilic or haloalkaliphilic phenotypes in other organisms [55, 59]. Although the regulation and cation transport stoichiometry of the homologs in " $\mathrm{Ca}$. N. alkalitolerans" remain unknown, the Mrp- and Nhafamily antiporters most likely exhibit important physiological roles in this organism and support its survival under haloalkaline conditions. Possibly, " $\mathrm{Ca}$. N. alkalitolerans" can even combine its growth in dense flocks with the extrusion of protons by its numerous proton transporters thereby lowering the $\mathrm{pH}$ inside the flock [51].

One of the two $n h a B$ genes present in the " $C a$. $\mathrm{N}$. alkalitolerans" genome is located in an interesting genomic region that also contains all genes encoding the group 3 Mrp-type $\mathrm{Na}^{+} / \mathrm{H}^{+}$antiporter (Fig. S8). The two genes downstream from $m r p D$ display sequence similarity to the NADH dehydrogenase (complex I) subunits NuoM and NuoL. However, based on the genomic context they are more likely additional $m r p A$ - and/or $m r p D$-like genes, as these $\mathrm{Na}^{+} / \mathrm{H}^{+}$antiporter subunits are evolutionary related to NuoM and NuoL [61]. Multiple copies of subunits NuoM and NuoL of the NADH dehydrogenase are encoded elsewhere in the genome, partially in larger nио operons (see Table S3). Moreover, the locus contains one gene coding for the low-affinity, high flux $\mathrm{Na}^{+} / \mathrm{HCO}_{3}{ }^{-}$uptake symporter BicA [62] and gene $\operatorname{mot} B$ encoding a $\mathrm{H}^{+}$-translocating flagellar motor component (Fig. S8). In the haloalkalitolerant cyanobacterium Aphanothece halophytica, a similar clustering of bicA with genes coding for $\mathrm{Na}^{+} /$ $\mathrm{H}^{+}$antiporters has been described. The authors proposed a model of cooperation between these transporters, where $\mathrm{Na}^{+}$extruded by the $\mathrm{Na}^{+} / \mathrm{H}^{+}$antiporters could drive the uptake of $\mathrm{HCO}_{3}{ }^{-}$by BicA under alkaline conditions when $\mathrm{CO}_{2}$ becomes limiting [63]. Sodium-driven import of $\mathrm{HCO}_{3}{ }^{-}$could be an essential feature for " $\mathrm{Ca}$. N. alkalitolerans", because bicarbonate is the main source of inorganic carbon for autotrophic organisms, but becomes less accessible at high $\mathrm{pH}>10$ [55]. A carbonic anhydrase, which is also present in the genome (Fig. 5, Table S3), can convert the imported $\mathrm{HCO}_{3}{ }^{-}$to $\mathrm{CO}_{2}$ for carbon fixation via the reductive tricarboxylic acid cycle (Fig. 5).

Since cytoplasmic $\mathrm{K}^{+}$accumulation may compensate for $\mathrm{Na}^{+}$toxicity at elevated intracellular $\mathrm{pH}$ [64], many alkaliphiles retain an inward directed $\mathrm{K}^{+}$gradient [55]. The potassium uptake transporters of the Trk family contribute to $\mathrm{pH}$ and $\mathrm{K}^{+}$homeostasis of halo- and/or alkaliphiles [55]. TrkAH catalyzes the $\mathrm{NAD}^{+}$-regulated uptake of $\mathrm{K}^{+}$possibly coupled with $\mathrm{H}^{+}$import [65]. Moreover, kinetic experiments revealed that TrkAH of the gammaproteobacterium Alkalimonas amylolytica is salt-tolerant and functions optimally at $\mathrm{pH}>8.5$ [66]. "Ca. N. alkalitolerans" encodes a TrkAH complex (Fig. 5, Table S3), which may be a specific adaptation to its haloalkaline environment as no homologous $\mathrm{K}^{+}$transporter has been identified yet in any other NOB genome. Under more neutral $\mathrm{pH}$ conditions, Kef-type $\mathrm{K}^{+}$efflux pumps, which are present in two copies in the " $\mathrm{Ca}$. N. alkalitolerans" genome, could excrete excess $\mathrm{K}^{+}$(Fig. 5, Table S3).

\section{Adaptations of the energy metabolism}

Aside from the different cation transporters (see above), "Ca. N. alkalitolerans" also encodes several mechanisms for cation homeostasis that are linked to membrane-bound electron transport and energy conservation. Like in other aerobic alkaliphiles [56], ATP synthesis is likely catalyzed by a canonical, $\mathrm{H}^{+}$-translocating $\mathrm{F}_{1} \mathrm{~F}_{\mathrm{O}}$-ATPase (Fig. 5, Table S3). In addition, the genome contains all genes of a predicted $\mathrm{Na}^{+}$-translocating N-ATPase [67] (Fig. 5, Fig. S9, Table S3). N-ATPases form a separate subfamily of F-type ATPases and have been suggested to be ATP-driven ion pumps that extrude $\mathrm{Na}^{+}$cations [67] or $\mathrm{H}^{+}$[68]. The $c$ subunit of the N-ATPase in the genome of " $\mathrm{Ca}$. N. alkalitolerans" contains the typical amino acid motifs for $\mathrm{Na}^{+}$ binding and transport [67] (Fig. S10). Subunits $a$ and $c$ of 
the N-ATPase, which are involved in ion transport, are most similar to homologs from the halotolerant, sulfate-reducing Desulfomicrobium baculatum (81.5\% AA identity) and the haloalkalitolerant, sulfur-oxidizing Sulfuricella denitrificans (88.2\% AA identity), respectively. Hence, in " $\mathrm{Ca}$. N. alkalitolerans", the N-ATPase may contribute to the maintenance of $\Delta \Psi$, the generation of a sodium motive force (SMF), and salt resistance (Fig. 5).

The genome of " $\mathrm{Ca}$. N. alkalitolerans" encodes two different types of NADH:quinone oxidoreductase (complex I of the electron transport chain) (Fig. 5, Table S3). Firstly, the organism possesses all 14 genes of type I NADH dehydrogenase (nuoA to nuoN). They are present in one to three copies each. The nuo genes are mostly clustered at several genomic loci (Table S3) and are most similar to either of the two nuo operons present in Nitrospira defluvii [39], with AA identities between $41 \%$ and $90 \%$. As mentioned above, nuoL/M-like genes at loci without other nиo genes might represent subunits of cation antiporters.

The genome furthermore contains a locus encoding all six subunits of a $\mathrm{Na}^{+}$-dependent $\mathrm{NADH}$ :quinone oxidoreductase (Nqr or type III NAD dehydrogenase) (Fig. 5, Table S3). The locus is situated on a single contig in the vicinity of transposase genes, indicating that " $C a$. N. alkalitolerans" might have received this type of complex I by lateral gene transfer. The gene of subunit $\mathrm{E}$, which takes part in $\mathrm{Na}^{+}$translocation [69], is most similar to a homolog in the ammonia-oxidizing bacterium Nitrosomonas nitrosa (86\% AA identity).

The metabolic model for N. defluvii [39] assumes that two different versions of the $\mathrm{H}^{+}$-dependent complex I (Nuo) are used for forward or reverse electron transport, respectively. Nitrospira possess a canonical Nuo that is likely used for PMF generation during the forward flow of lowpotential electrons from the degradation of intracellular glycogen or from hydrogen as an alternative substrate (see also below). In addition, reverse electron transport is essential in NOB to generate reducing power for $\mathrm{CO}_{2}$ fixation. In Nitrospira, a second (modified) form of Nuo with duplicated proton-translocating NuoM subunits might use PMF to lift electrons from quinol to ferredoxin [70]. The reduced ferredoxin is required for $\mathrm{CO}_{2}$ fixation via the rTCA cycle. As expected, " $\mathrm{Ca}$. N. alkalitolerans" possesses these two Nuo forms that are conserved in other characterized Nitrospira members. In addition, the $\mathrm{Na}^{+}$-dependent Nqr complex might function in two directions in " $\mathrm{Ca}$. N. alkalitolerans" as well. During forward electron flow, Nqr would contribute to SMF generation (Fig. 5). Reverse operation of the Nqr could generate NADH while importing $\mathrm{Na}^{+}$, thus utilizing SMF for the reduction of $\mathrm{NAD}^{+}$with electrons derived from quinol (Fig. 5). Hence, the two types of complex I are likely involved in essential electron transport and the fine-tuning of PMF and SMF. They probably cooperate with the $\mathrm{Na}^{+}$- and the $\mathrm{H}^{+}$-translocating ATPases and the various cation transporters (see above) to adjust the cytoplasmic ion concentrations and the membrane potential in response to the environmental salinity and $\mathrm{pH}$.

In addition to a novel " $b d$-like" cytochrome c oxidase, which is commonly found in Nitrospira genomes [16, 39], the genome of " $\mathrm{Ca}$. N. alkalitolerans" contains a locus with fused genes for a $c b b_{3}$-type cytochrome c oxidase (Fig. 5, Table S3) similar to the one present in the marine nitrite oxidizer Nitrospina gracilis [41]. The $c b b_{3}$-type terminal oxidases usually exhibit high affinities for $\mathrm{O}_{2}$ [71] and may allow "Ca. N. alkalitolerans" to sustain respiration at low oxygen levels.

Interestingly, " $\mathrm{Ca}$. N. alkalitolerans" encodes two different hydrogenases and the accessory proteins for hydrogenase maturation (Fig. 5, Table S3). First, it possesses a group 2a uptake hydrogenase that is also found in N. moscoviensis, which can grow autotrophically on $\mathrm{H}_{2}$ as the sole energy source [16]. Second, "Ca. N. alkalitolerans" codes for a putative bidirectional group $3 \mathrm{~b}$ (sulf)hydrogenase that also occurs in other NOB and in comammox Nitrospira [18, 41] but has not been functionally characterized in these organisms. Experimental confirmation of $\mathrm{H}_{2}$ utilization as an alternative energy source and electron donor by " $\mathrm{Ca}$. N. alkalitolerans" is pending. However, we assume that this capability would confer ecophysiological flexibility, especially if nitrite concentrations fluctuate and $\mathrm{H}_{2}$ is available at oxic-anoxic boundaries in biofilms or upper sediment layers. While electrons from the group $2 \mathrm{a}$ hydrogenase are probably transferred to quinone [16], the group 3b hydrogenase might reduce $\mathrm{NAD}^{+}$[41] and fuel forward electron transport through the Nuo and Nqr complexes (see above).

\section{Osmoadaptation}

The intracellular accumulation of compatible solutes is an important mechanism allowing microorganisms to withstand the high osmotic pressure in saline habitats [55]. " $\mathrm{Ca}$. N. alkalitolerans" has the genetic capacity to synthesize or import the compatible solutes trehalose, glycine betaine, and glutamate (Fig. 5). For trehalose synthesis the gene treS of trehalose synthase (Table S3), which enables trehalose synthesis from maltose, is present. The genes opuD and ориCB for glycine betaine import (Table S3) have been identified in the marine Nitrospina gracilis [41], but not yet in any Nitrospira species. For glutamate synthesis, the genes gltB and gltD were identified (Table S3). They code for the alpha and beta subunits of glutamate synthase, which catalyzes L-glutamate synthesis from L-glutamine and 2oxoglutarate with NADPH as cofactor. In addition, we identified adaptations of " $\mathrm{Ca}$. N. alkalitolerans" to the low availability of iron and the presence of toxic arsenite in saline-alkaline systems (Supplementary text). 


\section{Conclusions}

This study shows that diverse Nitrospira phylotypes are able to colonize saline-alkaline lakes, and that members of these lineages can carry out chemolithoautotrophic nitrite oxidation under strongly alkaline conditions up to $\mathrm{pH}$ 10.5. The genomic analysis of the newly cultured Nitrospira species "Ca. Nitrospira alkalitolerans" has revealed several adaptive features, many of which are also found in other haloalkalitolerant or -philic microorganisms but are missing in other characterized NOB. These results extend our picture of nitrogen cycling in extreme habitats and push the known limits of nitrite oxidation to an unusually high $\mathrm{pH}$. The presence of hydrogenase genes in " $\mathrm{Ca}$. N. alkalitolerans" suggests that alkalitolerant NOB can utilize alternative energy metabolisms and thus share at least part of the physiological versatility known from their neutrophilic relatives [13, 16, 17, 72]. As a next step it will be crucial to determine which ammonia oxidizers and/or comammox organisms coexist with alkalitolerant NOB and drive nitrification in saline-alkaline ecosystems.

\section{Data availability}

The raw, demultiplexed amplicon sequencing datasets obtained in this study have been deposited at the European Nucleotide Archive (ENA) database under study accession number PRJEB34917. The raw metagenomic sequence reads obtained from the " $\mathrm{Ca}$. N. alkalitolerans" enrichment culture have been deposited at ENA under study accession number PRJEB34830. The metagenome assembled (MAG) sequence and associated annotations of " $\mathrm{Ca}$. N. alkalitolerans" are publicly available in MicroScope [73].

Acknowledgements The authors thank Beate Pitzl from the Biological Station WasserCluster Lunz, Austria for chemical analysis and Zsófia Horváth for help with sample collection. We are further grateful to Sebastian Lücker for developing and sharing a Nitrospina nxrB reverse primer sequence. Queralt Güell-Bujon is acknowledged for maintaining and optimizing growth conditions of enrichments. This research was supported by the Austrian Science Fund (FWF) grants T938 (to AD), and P25231-B21 and P27319-B21 (both to HD).

Author contributions $\mathrm{AD}$ and $\mathrm{HD}$ conceived the study. AD took the samples, performed the physiological experiments and analyzed the data. AD, KK, HK, MS, JS set up the enrichments and collected data. CWH, SMK and MA processed the amplicon and metagenomic raw data. AD performed phylogenetic and comparative genomic analyses. $\mathrm{AD}$ and $\mathrm{HD}$ wrote the manuscript with input from all authors.

\section{Compliance with ethical standards}

Conflict of interest The authors declare that they have no conflict of interest.
Publisher's note Springer Nature remains neutral with regard to jurisdictional claims in published maps and institutional affiliations.

Open Access This article is licensed under a Creative Commons Attribution 4.0 International License, which permits use, sharing, adaptation, distribution and reproduction in any medium or format, as long as you give appropriate credit to the original author(s) and the source, provide a link to the Creative Commons license, and indicate if changes were made. The images or other third party material in this article are included in the article's Creative Commons license, unless indicated otherwise in a credit line to the material. If material is not included in the article's Creative Commons license and your intended use is not permitted by statutory regulation or exceeds the permitted use, you will need to obtain permission directly from the copyright holder. To view a copy of this license, visit http://creativecommons. org/licenses/by/4.0/.

\section{References}

1. Daims H, Nielsen JL, Nielsen PH, Schleifer K-H, Wagner M. In situ characterization of Nitrospira-like nitrite-oxidizing bacteria active in wastewater treatment plants. Appl Environ Microbiol. 2001;67:5273-84.

2. Bartosch S, Hartwig C, Spieck E, Bock E. Immunological detection of Nitrospira-like bacteria in various soils. Micro Ecol. 2002;43:26-33.

3. Poly F, Wertz S, Brothier E, Degrange V. First exploration of Nitrobacter diversity in soils by a PCR cloning-sequencing approach targeting functional gene nxrA. FEMS Microbiol Ecol. 2008;63:132-40.

4. Lebedeva EV, Off S, Zumbrägel S, Kruse M, Shagzhina A, Lücker $S$, et al. Isolation and characterization of a moderately thermophilic nitrite-oxidizing bacterium from a geothermal spring. FEMS Microbiol Ecol. 2011;75:195-204.

5. Füssel J, Lam P, Lavik G, Jensen MM, Holtappels M, Günter M, et al. Nitrite oxidation in the Namibian oxygen minimum zone. ISME J. 2012;6:1200-9.

6. Beman JM, Leilei Shih J, Popp BN. Nitrite oxidation in the upper water column and oxygen minimum zone of the eastern tropical North Pacific Ocean. ISME J. 2013;7:2192-205.

7. Edwards TA, Calica NA, Huang DA, Manoharan N, Hou W, Huang L, et al. Cultivation and characterization of thermophilic Nitrospira species from geothermal springs in the US Great Basin, China, and Armenia. FEMS Microbiol Ecol. 2013;85:283-92.

8. Daims H, Lücker S, Wagner M. A new perspective on microbes formerly known as nitrite-oxidizing bacteria. Trends Microbiol. 2016;24:699-712.

9. Sun, X., Kop, L.F.M., Lau, M.C.Y. et al. Uncultured Nitrospinalike species are major nitrite oxidizing bacteria in oxygen minimum zones. ISME J 2019;13:2391-402.

10. Juretschko S, Timmermann G, Schmid M, Schleifer K-H, Pommerening-Röser A, Koops H-P, et al. Combined molecular and conventional analyses of nitrifying bacterium diversity in activated sludge: Nitrosococcus mobilis and Nitrospira-like bacteria as dominant populations. Appl Environ Microbiol. 1998;64:3042-51.

11. Freitag TE, Chang L, Clegg CD, Prosser JI. Influence of inorganic nitrogen management regime on the diversity of nitrite-oxidizing bacteria in agricultural grassland soils. Appl Environ Microbiol. 2005;71:8323-34.

12. Daebeler A, Bodelier PL, Yan Z, Hefting MM, Jia Z, Laanbroek HJ. Interactions between Thaumarchaea, Nitrospira and methanotrophs modulate autotrophic nitrification in volcanic grassland soil. ISME J. 2014;8:2397-410. 
13. Gruber-Dorninger C, Pester M, Kitzinger K, Savio DF, Loy A, Rattei $\mathrm{T}$, et al. Functionally relevant diversity of closely related Nitrospira in activated sludge. ISME J. 2015;9: 643-55.

14. Lebedeva EV, Alawi M, Maixner F, Jozsa P-G, Daims H, Spieck E. Physiological and phylogenetic characterization of a novel lithoautotrophic nitrite-oxidizing bacterium, 'Candidatus Nitrospira bockiana'. Int J Syst Evol Microbiol. 2008;58:242-50.

15. Off S, Alawi M, Spieck E. Enrichment and physiological characterization of a novel Nitrospira-like bacterium obtained from a marine sponge. Appl Environ Microbiol. 2010;76:4640-6.

16. Koch H, Galushko A, Albertsen M, Schintlmeister A, GruberDorninger C, Lucker S, et al. Growth of nitrite-oxidizing bacteria by aerobic hydrogen oxidation. Science. 2014;345:1052-4.

17. Koch H, Lücker S, Albertsen M, et al. Expanded metabolic versatility of ubiquitous nitrite-oxidizing bacteria from the genus Nitrospira. Proc Natl Acad Sci U S A. 2015;112:11371-6.

18. Daims H, Lebedeva EV, Pjevac P, Han P, Herbold C, Albertsen $\mathrm{M}$, et al. Complete nitrification by Nitrospira bacteria. Nature. 2015;528:504-9.

19. van Kessel MAHJ, Speth DR, Albertsen M, Nielsen PH, Op den Camp HJM, Kartal B, et al. Complete nitrification by a single microorganism. Nature. 2015;528:555-9.

20. Grant WD. Alkaline environments and biodiversity. Extremophiles. Oxford, UK: UNESCO, Eolss Publishers; 2006.

21. Carini SA, Joye SB. Nitrification in Mono Lake, California: activity and community composition during contrasting hydrological regimes. Limnol Oceanogr. 2008;53:2546-57.

22. Antony CP, Kumaresan D, Hunger S, Drake HL, Murrell JC, Shouche YS. Microbiology of Lonar Lake and other soda lakes. ISME J. 2013;7:468-76.

23. Keshri J, Mishra A, Jha B. Microbial population index and community structure in saline-alkaline soil using gene targeted metagenomics. Microbiol Res. 2013;168:165-73.

24. Sorokin DY, Berben T, Melton ED, Overmars L, Vavourakis CD, Muyzer G. Microbial diversity and biogeochemical cycling in soda lakes. Extremophiles. 2014;18:791-809.

25. Johnson SS, Chevrette MG, Ehlmann BL, Benison KC. Insights from the metagenome of an acid salt lake: the role of biology in an extreme depositional environment. PloS One. 2015;10:e0122869.

26. Sorokin DY, Banciu HL, Muyzer G. Functional microbiology of soda lakes. Curr Opin Microbiol. 2015;25:88-96.

27. Lanzén A, Simachew A, Gessesse A, Chmolowska D, Jonassen I, Øvreås L. Surprising prokaryotic and eukaryotic diversity, community structure and biogeography of Ethiopian soda lakes. PLoS One. 2013;8:e72577.

28. Khmelenina YN, Eshinimaev BT, Kalyuzhnaya MG, Trotsenko YA. Potential activity of methane and ammonium oxidation by methanotrophic communities from the soda lakes of southern Transbaikal. Microbiology. 2000;69:460-5.

29. Sorokin DY, Muyzer G, Brinkhoff T, Kuenen JG, Jetten MSM. Isolation and characterization of a novel facultatively alkaliphilic Nitrobacter species, N. alkalicus sp. nov. Arch Microbiol. 1998; 170:345-52.

30. Tiago I, Veríssimo A. Microbial and functional diversity of a subterrestrial high $\mathrm{pH}$ groundwater associated to serpentinization. Environ Microbiol. 2013;15:1687-706.

31. Boros E, Horváth ZS, Wolfram G, Vörös L. Salinity and ionic composition of the shallow astatic soda pans in the Carpathian Basin. Ann Limnol - Int J Limnol. 2014;50:59-69.

32. Krachler R, Korner I, Dvorak M, Milazowszky N, Rabitsch W, Werba F, et al. Die Salzlacken des Seewinkels: Erhebung des aktuellen ökologischen Zustandes sowie Entwicklung individueller Lackenerhaltungskonzepte für die Salzlacken des Seewinkels (2008-2011). Eisenstadt, Austria: Österreichischer Naturschutzbund; 2012.
33. Boros E, Nagy T, Pigniczki C. The effect of aquatic birds on the nutrient load and water quality of soda pans in Hungary. Acta Zool Hung. 2008;54:207-24.

34. Boros E, Pigniczki C, Sápi T, V.-Balogh K, Vörös L, Somogyi B. Waterbird-mediated productivity of two soda pans in the Carpathian Basin in Central Europe. Waterbirds. 2016;39:388-401.

35. Boros E, V.-Balogh K, Vörös L, Horváth Z. Multiple extreme environmental conditions of intermittent soda pans in the Carpathian Basin (Central Europe). Limnologica. 2017;62:38-46.

36. DEW. Deutsche Einheitsverfahren zur Wasser-, Abwasser-, und Schlammuntersuchung. ISO 6878-1-1986 and DIN 38405 D11-4 for ortho-phosphate and total phosphorus, ISO 7150-1 and DIN 38406 E5-1 for ammonium, ISO 7890-1-2-1986 and DIN 38405D9 for nitrate, EN ISO 11905-1 for total nitrogen. Wiley-VCH; Weinheim, Germany 2007.

37. Angel R, Claus P, Conrad R. Methanogenic archaea are globally ubiquitous in aerated soils and become active under wet anoxic conditions. ISME J. 2012;6:847.

38. Emms DM, Kelly S. OrthoFinder: solving fundamental biases in whole genome comparisons dramatically improves orthogroup inference accuracy. Genome Biol. 2015;16:157.

39. Lücker S, Wagner M, Maixner F, Pelletier E, Koch H, Vacherie B, et al. A Nitrospira metagenome illuminates the physiology and evolution of globally important nitrite-oxidizing bacteria. Proc Natl Acad Sci. 2010;107:13479-84.

40. Kits KD, Sedlacek CJ, Lebedeva EV, Han P, Bulaev A, Pjevac P, et al. Kinetic analysis of a complete nitrifier reveals an oligotrophic lifestyle. Nature. 2017;549:269-72.

41. Lücker S, Nowka B, Rattei T, Spieck E, Daims H. The genome of Nitrospina gracilis illuminates the metabolism and evolution of the major marine nitrite oxidizer. Front Microbiol. 2013;4:27.

42. Pester M, Maixner F, Berry D, Rattei T, Koch H, Lücker S, et al. $\mathrm{NxrB}$ encoding the beta subunit of nitrite oxidoreductase as functional and phylogenetic marker for nitrite-oxidizing Nitrospira. Environ Microbiol. 2014;16:3055-71.

43. Watson SW, Bock E, Valois FW, Waterbury JB, Schlosser U. Nitrospira marina gen. nov. sp. nov.: a chemolithotrophic nitriteoxidizing bacterium. Arch Microbiol. 1986;144:1-7.

44. Taylor MW, Radax R, Steger D, Wagner M. Sponge-associated microorganisms: evolution, ecology, and biotechnological potential. Microbiol Mol Biol Rev. 2007;71:295-347.

45. Foesel BU, Gieseke A, Schwermer C, Stief P, Koch L, Cytryn E, et al. Nitrosomonas Nm143-like ammonia oxidizers and Nitrospira marina-like nitrite oxidizers dominate the nitrifier community in a marine aquaculture biofilm. FEMS Microbiol Ecol. 2008;63:192-204.

46. Keuter S, Kruse M, Lipski A, Spieck E. Relevance of Nitrospira for nitrite oxidation in a marine recirculation aquaculture system and physiological features of a Nitrospira marina-like isolate. Environ Microbiol. 2011;13:2536-47.

47. Haaijer SC, Ji K, van Niftrik L, et al. A novel marine nitriteoxidizing Nitrospira species from Dutch coastal North Sea water. Front Microbiol. 2013;4:60.

48. Richter M, Rosselló-Móra R. Shifting the genomic gold standard for the prokaryotic species definition. Proc Natl Acad Sci USA. 2009;106:19126-31.

49. Bowers RM, Kyrpides NC, Stepanauskas R, Harmon-Smith M, Doud D, Reddy TBK, et al. Minimum information about a single amplified genome (MISAG) and a metagenome-assembled genome (MIMAG) of bacteria and archaea. Nat Biotechnol. 2017;35:725-31.

50. Nogueira R, Melo LF. Competition between Nitrospira spp. and Nitrobacter spp. in nitrite-oxidizing bioreactors. Biotechnol Bioeng. 2006;95:169-75.

51. Charles CJ, Rout SP, Patel KA, Akbar S, Laws AP, Jackson BR, et al. Floc formation reduces the $\mathrm{pH}$ stress experienced by 
microorganisms living in alkaline environments. Appl Environ Microbiol. 2017;83:e02985-16.

52. Nowka B, Off S, Daims H, Spieck E. Improved isolation strategies allowed the phenotypic differentiation of two Nitrospira strains from widespread phylogenetic lineages. FEMS Microbiol Ecol. 2015;91:fiu031.

53. Schramm A, de Beer D, van den Heuvel JC, Ottengraf S, Amann R. Microscale distribution of populations and activities of Nitrosospira and Nitrospira spp. along a macroscale gradient in a nitrifying bioreactor: quantification by in situ hybridization and the use of microsensors. Appl Environ Microbiol. 1999;65: 3690-6.

54. Krulwich TA, Sachs G, Padan E. Molecular aspects of bacterial pH sensing and homeostasis. Nat Rev Microbiol. 2011;9:330-43.

55. Banciu HL, Sorokin DY. Adaptation in haloalkaliphiles and natronophilic bacteria. In: Seckbach J, Oren A, Stan-Lotter H, editors. Polyextremophiles. Netherlands: Springer; 2013, pp 121-78.

56. Banciu HL, Muntyan MS. Adaptive strategies in the doubleextremophilic prokaryotes inhabiting soda lakes. Curr Opin Microbiol. 2015;25:73-9.

57. Swartz TH, Ikewada S, Ishikawa O, Ito M, Krulwich TA. The Mrp system: a giant among monovalent cation/proton antiporters? Extremophiles. 2005;9:345-54.

58. Ito M, Morino M, Krulwich TA. Mrp antiporters have important roles in diverse bacteria and archaea. Front Microbiol. 2017;8:2325.

59. Kuroda T, Mizushima T, Tsuchiya T. Physiological roles of three $\mathrm{Na}^{+} / \mathrm{H}^{+}$antiporters in the halophilic bacterium Vibrio parahaemolyticus. Microbiol Immunol. 2005;49:711-9.

60. Cheng B, Meng Y, Cui Y, Li C, Tao F, Yin H, et al. Alkaline response of a halotolerant alkaliphilic Halomonas strain and functional diversity of its $\mathrm{Na}^{+}\left(\mathrm{K}^{+}\right) / \mathrm{H}^{+}$antiporters. J Biol Chem. 2016;291:26056-65.

61. Moparthi VK, Kumar B, Al-Eryani Y, Sperling E, Górecki K, Drakenberg T, et al. Functional role of the MrpA- and MrpDhomologous protein subunits in enzyme complexes evolutionary related to respiratory chain complex I. Biochim Biophys Acta BBA - Bioenerg. 2014;1837:178-85.
62. Price GD. Inorganic carbon transporters of the cyanobacterial CO2 concentrating mechanism. Photosynth Res. 2011;109:47-57.

63. Fukaya F, Promden W, Hibino T, Tanaka Y, Nakamura T, Takabe T. An Mrp-like cluster in the halotolerant cyanobacterium Aphanothece halophytica functions as a $\mathrm{Na}^{+} / \mathrm{H}^{+}$antiporter. Appl Environ Microbiol. 2009;75:6626-9.

64. Padan E, Krulwich TA. Sodium stress. Bacterial stress responses. Washington, DC: ASM Press; 2000. pp 117-30.

65. Domene C, Furini S. Molecular dynamics simulations of the TrkH membrane protein. Biochemistry. 2012;51:1559-65.

66. Guo Y, Xue Y, Liu J, Wang Q, Ma Y. Characterization and function analysis of a Halo-alkaline-adaptable Trk $\mathrm{K}^{+}$uptake system in Alkalimonas amylolytica strain N10. Sci China C Life Sci. 2009;52:949-57.

67. Dibrova DV, Galperin MY, Mulkidjanian AY. Characterization of the N-ATPase, a distinct, laterally transferred $\mathrm{Na}^{+}$-translocating form of the bacterial F-type membrane ATPase. Bioinformatics. 2010;26:1473-6.

68. Schulz S, Wilkes M, Mills DJ, Kühlbrandt W, Meier T. Molecular architecture of the N-type ATPase rotor ring from Burkholderia pseudomallei. EMBO Rep. 2017;18:526-35.

69. Verkhovsky MI, Bogachev AV. Sodium-translocating NADH: quinone oxidoreductase as a redox-driven ion pump. Biochim Biophys Acta BBA - Bioenerg. 2010;1797:738-46.

70. Chadwick GL, Hemp J, Fischer WW, Orphan VJ. Convergent evolution of unusual complex I homologs with increased proton pumping capacity: energetic and ecological implications. ISME J. 2018;12:2668-80.

71. Cosseau C, Batut J. Genomics of the ccoNOQP-encoded cbb3 oxidase complex in bacteria. Arch Microbiol. 2004;181:89-96.

72. Füssel J, Lücker S, Yilmaz P, Nowka B, van Kessel MAHJ, Bourceau P, et al. Adaptability as the key to success for the ubiquitous marine nitrite oxidizer Nitrococcus. Sci Adv. 2017;3: e1700807.

73. Vallenet D, Belda E, Calteau A, Cruveiller S, Engelen S, Lajus A, et al. MicroScope-an integrated microbial resource for the curation and comparative analysis of genomic and metabolic data. Nucleic Acids Res. 2013;41:D636-D647. 